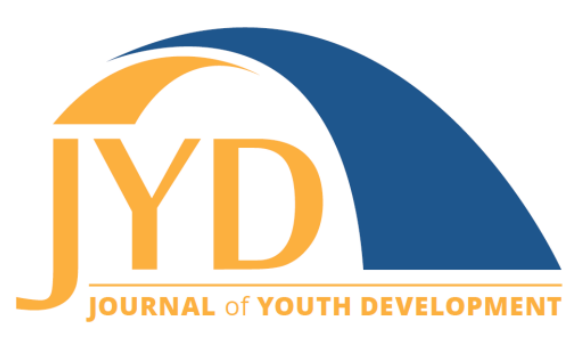

http://jyd. pitt. edu/ | Vol. 14 Issue 1 DOI 10.5195/jyd.2019.729 | ISSN 2325-4017 (online)

\title{
Girls' Experiences in a Positive Youth Development Sport Program: Developing a Participant-Centered Space
}

Kelly C. Johnston

Baylor University

kelly_johnston@baylor.edu

Risto Marttinen

George Mason University

rmarttin@gmu.edu

\section{Ray N. Fredrick, III}

Queen's College, City University of New York

ray.fredrick@qc.cuny.edu

\section{Vidya R. Bhat}

Eastchester Union Free School District

vrb206@nyu.edu

\begin{abstract}
School-age youth of low-income, urban communities frequently experience systemic inequities, such as limited access to healthy foods, lack of space for physical activity, higher drop-out rates, lower academic performance, and escalating rates of neighborhood violence. These inequities are often exacerbated for girls of color. After-school programs hold great potential for countering these issues, particularly when guided by a positive youth development (PYD) model. This qualitative study examined girls' experiences in one after-school PYD program called REACH (Reflective Educational Approach to Character and Health). The authors discuss the ways in which the co-creation of a participant-centered space and interrelated connections between participants and program elements contributed to the girls'experiences of the program in particular ways. These findings enhance understandings on how girls' experiences shape relational dimensions of the PYD model, particularly PYD through sport. The authors conclude with implications for future research, suggesting enhancing the PYD through sport framework through activistbased research as a particularized means for further researching girls' experiences in after-school PYD programs seeking interdisciplinary integration.
\end{abstract}

(c) $\mathbf{E Y}$ New articles in this journal are licensed under a Creative Commons Attribution 4.0 License. This journal is published by the University Library System, University of Pittsburgh and is cosponsored by the University of Pittsburgh Press. The Journal of Youth Development is the official peer-reviewed publication of the National Association of Extension 4-H Agents and the National AfterSchool Association. 
Girls' Experiences in a PYD Sport Program

Key words: after-school, positive youth development, sport, girls, experiences

\section{Developing a Participant-Centered Space}

Increased attention to after-school programs has influenced the educational field in myriad ways (After School Alliance, 2016; Deutsch, Blyth, Kelley, Tolan, \& Lerner, 2017; Lerner, Almerigi, Theokas, \& Lerner, 2005). These programs can reduce systemic inequities many youth experience in high-poverty urban communities. For example, due to structural racialization (Elsheikh \& Barhoum, 2013), most high-poverty neighborhoods have limited access to healthy food options and outdoor space (Afterschool Alliance, 2016). Additionally, the lack of funding and resources results in schools that have a higher prevalence of academic issues, such as a high dropout rate and lower test scores (Afterschool Alliance, 2016; Evans, 2004). These facts, coupled with higher crime rates (Evans, 2004; Hirsch, B. J. et al., 2000), demonstrate the harsh realities for families living in high-poverty, urban neighborhoods. Concurrently, many urban, low-socioeconomic areas provide fewer opportunities for youth to be physically active due to safety concerns (Molnar, Gortmaker, Bull, \& Buka, 2004; Sanderson \& Richards, 2010).

Research has found, however, that youth in urban, low-socioeconomic and high-crime areas benefit more than any other population from after-school programs (Vandell \& Shumow, 1999), demonstrating the powerful role of interventions such as after-school programs in combatting the systemic inequities people in urban areas experience. After-school programs can also provide support in academic subjects in addition to opportunities for increased physical activity (PA). Research shows a link between fitness and academic achievement in which aerobic capacity is positively associated with academic achievement (Castelli, Hillman, Buck, \& Erwin 2007). Yet youth with the lowest levels of PA, such as those living in urban environments, often have limited access to programs that take place at school or utilize school resources (Basch, 2011; Shen, 2017).

Research further demonstrates the challenges facing young girls living in under-resourced, urban areas. Research on girls of color, particularly African-American girls, has shown they are the least physically active demographic group (Belcher et al., 2010; Centers for Disease Control and Prevention, 2007). This reported inactivity could be linked to the fact that African-American girls living in urban areas experience high poverty rates, increased violence, and limited places to exercise which leaves school-sponsored after-school sports programs as the only organized opportunity to participate in intentional physical activity (Shen, 2017; Staurowsky et al., 2009). 


\section{Girls' Experiences in a PYD Sport Program}

Yet research demonstrates positive outcomes for girls who participate in PA, including but not limited to, overall health and well-being (Staurowsky et al., 2009), an increase in academic achievement (Crosnoe, 2002), and a greater likelihood to attend college and earn a degree in higher education (Troutman \& Dufur, 2007).

Given the need for youth in urban areas to access safe spaces that offer opportunities for physical activity and academic enrichment, after-school programs offer an ideal way for girls of color to participate in a safe and supportive environment. Even more so, understanding the experiences of young people in these types of programs is important for identifying the processes that contribute to outcomes as well as considering how their experiences counter other lived experiences as a result of systemic inequities in their communities. Thus, this qualitative case study examined young girls' experiences in an after-school, sports-based program to better understand how they experienced the program and what processes contributed to these experiences. In the following sections, we first describe the positive youth development through sport model, also our theoretical framework, used to guide the implementation of an after-school program. We then discuss the methods and introduce the participants and context of this study. Finally, we present findings from the study and discuss implications.

\section{Theoretical Framework: Positive Youth Development Through Sport Model}

Positive youth development (PYD) is a promising approach for after-school programs seeking to mitigate social inequities through offering safe, participatory spaces for youth. PYD is different from traditional child development models, which often situate youth through the lens of prevention (Holt et al., 2017; Lerner, 2005; Roth \& Brooks-Gunn, 2003), such as keeping youth away from substance abuse, violence, and unhealthy habits (Smith, 2007). While these approaches stem from a deficit-based view, PYD takes, as its name implies, a developmental, strengths-based approach in supporting youth by cultivating their talents and strengths in a variety of areas. PYD moves away from the deficit notion that youth behavior is unchangeable and instead advances the view that the potential for systematic change in behavior exists as a result of mutually influential relationships between youth and contextual factors such as family, community, and culture (Lerner, 2004).

Lerner (2004) proposed key competencies of successful community-based PYD programs that foster such relationships. The 5 Cs of PYD, competence (positive view of one's actions), confidence (internal sense of self-worth and self-efficacy), connection (positive bonds with 
Girls' Experiences in a PYD Sport Program

people and institutions related to family, school and community), character (fostering respect for others and moral responsibility), and caring (sense of sympathy and empathy for others), serve as the pillars of many PYD models (for examples, see Iachini, Beets, Ball \& Lohman, 2014; Weiss, Stuntz, Bhalla, Bolter, \& Price, 2013). A sixth competency of contribution (giving back to one's community) is reached when all of these are enacted (Lerner, 2004; 2005).

More recently, Holt et al., (2017) presented a grounded theory in PYD through sports. Holt and colleagues explained that much of the PYD theory was not developed for sport programs and provided an alternate framework that builds off of extensive literature from successful sport programs that delivered a PYD model. The model presented revolves around (a) PYD climate, (b) PYD outcomes, and (c) a life skills focus. The PYD climate involves having empathetic relationships with adults (coaches/teachers), positive interactions with peers, and supportive parents. PYD outcomes refer to the personal, social and physical outcomes of youth sport programs. The life skills focus integrates the competency of character by centering on role modeling positive behaviors and having high expectations for behavior and accountability.

This new PYD model through sport enhances the relational aspect of the original PYD model as proposed through the $5 \mathrm{Cs}$. The role of relationships, particularly adult relationships with youth participants, has been central to much of the literature on PYD after-school programs. Larson (2006) described the complexities adults must consider when determining their relational stance with youth participants. For instance, adults must have a grasp on the tenuous line between providing direction for youth but giving enough space to foster opportunities for youth agency. Program leaders' beliefs and understandings are integral to participants' development and experiences in PYD programs (Iachini, Bell, Lohman, Beets, \& Reynolds, 2016). Relational pedagogy is a vital aspect of the PYD model, especially for working with traditionally marginalized youth (Jones \& Deutsch, 2011).

Empirical research on after-school PYD programs focused on promoting girls' PA has highlighted the integrated nature of PA and other life components, such as developing knowledge of health and wellness, learning multiple sports, incorporating life skills and applying to other areas of one's life (Bean, Kendellen, \& Forneris, 2016), and developing physically as well as socially (Bean, Forneris, \& Halsall, 2014; Iachini et al., 2014). In focusing specifically on AfricanAmerican girls who live in urban areas, Shen (2017) found daily physical activity positively influenced academic performance. Additionally, through interviewing participants in one basketball-based program for African-American girls in an urban area, Olushola, Jones, Dixon, and Green (2013) identified the necessity of multifaceted programs that provide support beyond 
Girls' Experiences in a PYD Sport Program

participation in the sport, such as integration of core values (e.g., family, education, discipline, and civic engagement). Incorporating these supports, according to the girls, enhanced actual benefits of the program.

PYD scholars agree that while research on whether after-school programs benefit youth is important, focus is also needed on the particulars of these programs (Deutsch et al., 2017). We believe this is especially important for marginalized girls of color in urban, under-resourced communities. The PYD through sport framework (Holt et al., 2017) offers a focused lens on the relational aspect of PYD after-school programs, which we explored through this study

\section{Method}

This qualitative case study focused on the experiences of young, urban girls of color who participated in REACH (Reflective Educational Approach to Character and Health), an afterschool, PYD, sports-based program. Holt and colleagues' (2017) PYD through sport theoretically guided the study, allowing for an intensified focus on the relational aspects of the program that supported the multifaceted aims of REACH. These aims included the integration of physical activity through basketball, academic development through literacy-based activities, and cultivating a safe, participatory space. Thus, the main research question guiding this study was: What processes contributed to girls' experiences in the REACH after-school PYD program?

\section{Setting}

Weekly REACH sessions took place from October 2015 to May 2016 on Thursdays after school for $1 \frac{1}{2}$ hours in the school gym. The particular school in which the study took place served grades K-8 and was known as a community school, meaning it partnered with outside organizations that provided after-school programs for students as well as an on-site health clinic. School demographics consisted of 53\% Hispanic, $44 \%$ Black, and $1 \%$ Asian with $10 \%$ of these being English language learners and 31\% identified as students with special needs. The school was classified as Title I with $84 \%$ of students qualified for free or reduced lunch (New York City Department of Education, 2017).

In the previous year, REACH held sessions for an all-boys group at the same school that heavily focused on basketball skills and was limited to boys due to a shortage of personnel. Through conversations with site leaders and the school principal, the REACH leaders and researchers recognized the girls' desire to also participate in the REACH program. Girls were notified of the 
Girls' Experiences in a PYD Sport Program

new program by the after-school coordinator at the school in the beginning of the school year and chose to participate on a weekly basis. Thus, there were no particular criteria for participating in the REACH program and research study, and likewise, their participation in the program and research study was voluntary.

\section{Participants}

Youth Participants.

The demographics of the school were reflected in the REACH program, which consisted of 12 fourth- and fifth-grade girls. The girls' attendance fluctuated, with between five and eight girls in attendance each week. The focal participants for this study were the five fourth- and fifthgrade girls who regularly attended REACH. The girls all identified as either African-American or Latina. From the group of five regulars, the researchers invited all to sit down for a one-on-one interview at the end of the year, which was the end of the REACH program. Two of the girls, Alysha and Miriam (all names are pseudonyms), obtained written consent from parents and signed assent to complete these interviews and have them recorded.

\section{Coach and Other Attendees.}

The REACH coach, Amy, a White physical education teacher from another school, who was also getting her master's degree in physical education, led the girls in all sessions. Typically, two female community school supervisors, both who identified as African-American, and one female REACH researcher, who identifies as White, were also in attendance for the weekly sessions throughout the year. The researcher observed the REACH sessions but did not actively participate in them.

\section{Data Collection}

Data collection was based on each REACH session, which consisted of three main segments: active participation in reflection journals and related discussion, basketball skills practice with interwoven mini-discussions connecting back to the theme, and concluding discussion and challenge. These segments were designed in relation to REACH's overarching goal of integrating physical activity through basketball and academic development with a focus on literacy-based activities, which aligned with the Common Core State Standards focus on reading, writing, speaking, and listening (National Governors Association Center for Best Practices, Council of Chief State School Officers, 2010). Each week, Amy, a certified elementary education teacher, 
Girls' Experiences in a PYD Sport Program

led the girls through the session, while the researcher observed and took detailed field notes throughout the session.

The researcher sought to understand the experiences of the girls participating in the REACH program and the processes that contributed to these experiences. Thus, detailed field notes were recorded during each session and were discussed in detail with Amy after each session to include her feedback and observations. The girls' weekly written reflections and journal responses were used to triangulate findings; they provided an added insight into their girls' experiences in the program. Additionally, interviews were used to better understand the girls' experiences in REACH and further allowed for data saturation to occur. However, only two participants submitted signed parent/guardian permission forms allowing interviews, thus limiting the number of interview responses that could be included in the study.

\section{Data Analysis}

Two researchers independently coded data using the NVIVO 12 software (Melbourne, AUS) to help sort and organize the data. Analysis took place through a constant comparative method (Marshall \& Rossman, 2011). This method consisted of both open coding and axial coding. Open coding served as the first phase in which we read through all the data and while doing so, developed categories, in general, and codes, in particular, to disentangle the data.

Once we generated a list of categories and codes, we moved to axial coding. In this phase, we again reviewed the data, but this time we sought to evaluate how our codes and categories fit (or not) with different pieces of data. For example, if we developed particular categories and codes from the interviews, we explored how/if these worked with the data from the observations. Once the data were coded, these codes were analyzed to identify recurring themes, which constitute the findings for this study.

To maintain trustworthiness and enhance credibility, a peer reviewer reviewed all codes and provided written feedback to the researchers (Creswell \& Miller, 2000), and data were triangulated through interviews with the girls, field notes, informal interviews with Amy, and the girls' journal responses. 


\section{Findings}

Our analysis of the data presents two overarching themes describing the girls' experiences in the REACH program. Data included in these themes demonstrate the ways in which the cocreation of a participant-centered space privileged the girls' interests. Concurrently, data shows the interrelated connections between the girls and multiple aspects of REACH, including one another, their coach, literacy-based development, physical activity, and their community. Following the presentation of these findings, we conclude with a final discussion and implications for future directions.

\section{The Co-Creation of a Participant-Centered Space}

The unique co-creation of a participant-centered space contributed to the girls' experiences in REACH. Because social contexts are unique and fluid, such a conducive space could not simply be predetermined or given to the girls. Rather, they co-created it with Amy and the community school supervisors each week, building upon the experiences of the week before. All present stakeholders had a role in this, including the coach, supervisors, researcher, and of course, the girls themselves. Their actions were evident through the weekly field notes, which provided insight into the ways in which this space fluidly emerged.

For instance, Amy established the routine of the sessions, which consisted of a weekly reflection journal completed by participants, a word-of-the-week discussion, and then physical activity while also intentionally inviting the girls to determine how the routine would play out. With REACH occurring immediately after school, the girls consistently entered the gym vivaciously, exuding energy physically and vocally. While there was the intended routine for each REACH session, Amy relied on her instincts as a teacher and coach to discern how and when to let them take the lead, to relinquish control, and to share agency. For example, there were various occasions on which the girls seemed more interested in personal interaction with one another than the planned REACH element; these occurred sometimes during the weekly reflection completion time, the word-of-the-week discussion, or physical activity. When asked about these moments, Amy responded that she believed REACH needed to be a unique space for the girls distinct from school but still related to school. She went on to explain that, as a teacher, she understood the structure and demands the girls adhere to throughout the day, and that while she holds them to high expectations, REACH offers a way to do this a bit differently than school by remaining flexible with program elements while valuing the girls' interests, thus reframing the typical power imbalances present in teacher-student relationships. 
Valuing the girls' interest in basketball as a resource opened up an agentive space for learning and play, which also influenced the nuanced co-creation of the participant-centered space. In fact, analysis of the data suggests basketball, while a focal point of REACH, served also as a gateway for the girls to establish an after-school space characterized by enjoyment, in both physical activity through informal games and friendly competition as well as a forum for exploring new and unfamiliar concepts through word-of-the-week discussions.

To say the girls liked bringing in informal games as a normed part of the program would be an understatement. Alysha and Miriam's interview responses indicated that the informal games were their favorite part of REACH, and the weekly field notes support this conclusion as well. About midway through the academic year, Amy introduced a time for informal games at the end of each REACH session. As weeks went by, the girls asked about this game time more frequently. These physical activity-based games incorporated words of the week which were character related, such as teamwork, dedication, and communication, and provided Amy a platform, in addition to basketball, on which to discuss these concepts and integrate the character education component of REACH.

The co-creation of the participant-centered space was further developed through the integration of the word-of-the-week portion of REACH. While Amy determined this word each week and worked to interweave these throughout each session, she intentionally tuned into the girls' enjoyment of informal play and games. For example, Amy reflected on one weekly session, in which the word of the week was commitment. At the beginning of the session, the girls and Amy had defined and discussed this word, made personal connections to it, and used it in writing through their weekly reflection journals. Amy reflected on it in this way:

During the opening discussion the girls were asked to define commitment. They defined it as "working hard." We then came to settle on the definition: working hard and being dedicated to an activity or cause. We then discussed things they are committed to that were either basketball or non-basketball related. Most of the responses were centered on doing well in school and listening to their teacher. Before starting the physical part of the session, I challenged the girls to make a commitment for the day: to not talk when I was talking, to pay attention by doing what I asked them to do, and to not go off to the side and do whatever they want to do. 
While this real-time enactment of commitment was immediately circumstantial, it afforded Amy the opportunity to connect to the girls in that moment in time while also opening up an opportunity for the girls to respond. Amy assured the girls that if they stayed true to their commitment, they would earn free play at the end of their time together that day. Throughout the session, as the girls participated in the physical activities based on basketball skill drills and games, Amy periodically reminded the girls of their commitment. This seemed to serve as a motivator for the girls, as Amy noted:

At the end of the session I let the girls have 10 minutes of free time (to play a game of their choice) for staying with their commitment. When I told the girls this, most of them seemed surprised. I think it is important for the girls to see that if they mean what they say and do what they say they will do, then I will do the same. I see this as a great way to build relationships with the girls that are built on trust and respect.

Key to co-creating a participant-centered space was Amy's implementation in valuing the girls' experiences and incorporating program elements based on their participation.

\section{Valuing Participant Connections}

Each session segment, including word-of-the-week discussions, written and oral engagement with weekly reflection journals, and the physical activity portion, fostered and valued participant connections first and foremost. This aspect of the program placed emphasis on the girls' knowledge and experiences, valuing these as resources to build upon. Through analysis of field notes, interviews, and weekly reflection journals, we found the girls' interrelated connections merged across time and space. Specifically, participant connections within the REACH program elements were more entangled than simply one-directional. For example, participant connections with literacy-based activities, physical activity through games and basketball, and with one another and their personal lives ranged across different times and in different moments.

Connections emerged between the girls' lives and the words of the week. Word-of-the-week discussions served as the leading activity for each session. The girls came to expect this and knew to use their program binders to locate the weekly schedule and identify the word of the week. Words of the week, such as communication, response, and determination, focused the group's discussion, and though some of these concepts were initially unfamiliar to the girls, 
Girls' Experiences in a PYD Sport Program

their learning became possible through the flexible space created for literacy-based engagement with these terms. Aligning with the Common Core ELA Standards, Amy posed open-ended questions to facilitate participant-centered discussions based on the word of the week, including what the girls thought it meant, how they might use it in a sentence, and what this word meant in their own lives. Through its program elements, REACH incorporated this approach to literacy development to reinforce the integration of vocabulary, comprehension, and building on personal knowledge to deepen overall understanding (Hirsch, E. D., 2003). For example, the beginning of one such discussion between Amy and the girls went like this:

Amy: So the word of the week is determination. Who thinks they know what determination means?

Miriam: Brave?

Skye: When you have confidence and you don't give up and you're determined you're going to, let's talk about the test, you're determined you're going to pass the test.

Amy: Who else? What does determination mean?

Lisa: Determination means when you think you're going to give up but you're not.

Amy: Yes, like you're determined to make the basketball team.

These discussions offered the girls opportunities to connect with the word through identification and response, privileging their experiences over a predetermined definition. During their interviews, when asked about benefits they experienced from the program, Miriam and Alysha's responses included their learning of new words from each week. Specifically, Alysha mentioned this in relation to becoming a better writer while Miriam identified particular characteristics of the words, such as how to be respectful. When Miriam was asked about her learning of new words, she responded she became "a better writer by trying to learn how we use these words and basketball." These interviews were conducted near the end of the academic year, yet both girls recalled concepts introduced early in the program year, speaking of what these meant for their own lives.

The girls' engagement with the weekly reflection journals followed the word-of-the-week discussion, reinforcing these concepts as well as other aspects of the girls' lives, offering another intentional avenue for girls to make deeper connections. The weekly reflection journals consisted of seven questions to which the girls were to respond through writing and then would discuss collectively once all questions were responded to independently. These questions covered the topics of the word of the week, including how the word related to the girls' school, 
Girls' Experiences in a PYD Sport Program

basketball, or home life, as well as topics of physical activity, health, nutrition, personal focus, and accountability for personal actions on a day-to-day basis.

For example, one question on the weekly reflections asked:

What should you focus on most over the next week?
a. School
b. Family
c. Friends
d. Yourself
e. Your neighborhood/community
Why?

Each week, the girls responded to this question by circling their answers and then detailing in written form. One day, as the girls were independently responding in writing through these weekly reflections, Alysha began writing and interjected aloud:

I have to focus on everything! My school, family, neighbors and friends. Yeah, because I need to focus on my community because

I don't want my community looking dusty. I still got to focus on

my neighborhood, because it's MINE.

Her vocal emphasis on mine conveyed her intensity surrounding these entities, an intensity, we argue, that was evoked through her realized connections to these important people and places in her life.

Through word-of-the-week discussions and engagement with the weekly reflection guides, the girls practiced literacy skills, including reading, writing, speaking, and listening, all components integral to the Common Core State Standards (CCSS). The girls seemed to pick up on the shared aspects of literacy learning that occurred during REACH and that also occurred during school. At various times, they made verbal connections to school, particularly the upcoming state-mandated English language arts test.

To enhance the literacy aspect of the program and further strengthen the connections participants might make through literacy-based activities, Amy integrated an additional element to support the word-of-the-week and weekly reflection segments of the program. In doing so, she introduced The Crossover by Kwame Alexander, a poetry-based, young adult novel that 
Girls' Experiences in a PYD Sport Program

follows two young brothers whose lives are challenged through basketball and everyday life. The REACH program leaders designed a loose curriculum based on this text, in which the girls read a textual excerpt from the book, discussed recurring themes to identify the word of the week, and engaged in skills based on the CCSS, such as making predictions, analyzing character, and drawing conclusions, to name a few. Bringing in a text offered the girls opportunities to further connect in multiple ways, through literacy, character development, and to school. For instance, on one occasion Amy read aloud an excerpt and then engaged in a discussion with the girls:

Amy: When you think about this last page and our word of the week, determination, what comes to mind?

Miriam: He's determined that he's going to be able to play basketball.

Skye: What does the word determined mean?

Amy asks the group if someone can help supply a definition.

Lisa hesitates, seemingly searching for the words.

Amy: to never give up

Lisa: Yes, to never give up.

The girls and Amy continued the discussion by rereading part of the text and identifying how the main character displayed evidence of determination. Skye, who had asked the meaning for determination, then announced in connection to the character, "Like what I put on my [reflection journal], I never gave up on my test!"

Participants' connections became further enhanced and entangled during the physical activity portion of the program. These included their connections between their physical development in basketball as well as interactions with one another and concepts that had been introduced through the program. For example, the girls regularly participated in basketball skill drills and games, many of which promoted friendly competition. Amy would briefly introduce a particular skill each week through talking about it and then demonstrating it. Then the girls would practice through the activity introduced by Amy. Analysis of the field notes highlighted celebration, encouragement, and determination as recurring participant-initiated characteristics of this physical activity portion.

\section{Discussion}

Examining girls' experiences in the REACH program highlights the co-creation of a participantcentered space as well as the interrelated connections the girls made to one another, their 


\section{Girls' Experiences in a PYD Sport Program}

coach, literacy learning, physical activity, and their own lives. We drew on data to demonstrate what this space and these connections looked like through REACH. The co-creation of the participant-centered space emerged through valuing the girls' interests, knowledge, and personal lives. Although there were specified program elements that constituted the REACH curriculum, Amy privileged the girls above the program, opening opportunities for shaping the program based on their interests. These led to physical activity that incorporated basketball as well as informal games. The literacy-based activities, including word of the week, were also shaped based on the girls' responses and personal connections. Valuing the girls' interrelated connections that emerged from these program elements also contributed to the girls' experiences of the program.

In relation to the PYD through sport framework (Holt et al., 2017), these findings contribute understandings of how girls' experiences produce particular PYD climates and thus shape PYD outcomes. The co-created participant-centered space enhances relational understandings of the PYD coach, the participants, and the actual enactment of PYD program elements, including basketball and literacy-based activities. While related literature has emphasized the importance that the adult keep a youth-centered, balanced approach (e.g., Larson \& Walker, 2010), our findings demonstrate the interrelated nature of the adult and participants in co-creating a space based on the youth themselves. This interrelated nature is similar to the concept of relational flow (Markowitz, Deutsch, \& Lawrence, 2014) which highlights the relational aspects of enjoyment, interest, and concentration shared between people in a specific context. This is especially important for girls of color, because they are often the most marginalized population in relation to safe spaces in under-resourced urban areas, as well as physical activity.

In this study, the co-creation of the space, that is the actual enactment of the program elements of physical activity and literacy-based activities, led to interrelated connections for the girls, which empowered them to voice these connections and make choices that shaped the curriculum implementation. These choices led to enjoyable experiences of physical activity through basketball and informal play as well as meaningful connections among their lives, words of the week, reading comprehension, written reflection, and physical activity. These enactments tie into the life skills focus presented in the PYD through sport framework (Holt, et al., 2017), with the girls' connections leading to personal understanding and application related to themes of the week. This facet of life skills development can also be seen as contributing to the PYD climate, thus suggesting an iterative nature of PYD through sport rather than a linear one. 
Girls' Experiences in a PYD Sport Program

These findings move us to consider more closely girls of color and their experiences in afterschool programs seeking to provide safety and support for physical activity through a youth development approach. The processes of co-creating a participant-centered space and valuing participant connections through program elements hold important implications for the field as well as merging research and practice. For practice, these findings contribute further understanding on how valuing participants, in this case young girls of color, shapes the enactment of an after-school PYD program.

\section{Limitations and Next Steps}

There are several limitations to consider from this study. In conducting research with youth, ethics are extremely important, including following proper protocols for obtaining consent and assent from participants. In doing so, our sample size remained relatively small, with a core of five girls and only two one-on-one interviews. Attention to processes for communicating with participants and their guardians could strengthen future studies seeking to examine participants' experiences in similar programs. Additionally, as we began analyzing more data near the end of the program year, we realized the ways in which other theories might enhance not only the REACH program, but also our methodological approach, particularly in more actively including the girls in the actual research process.

Thus, implications for future research include enhancing the PYD through sport framework with feminist-based theoretical frameworks that will productively guide researchers in more nuanced ways to understand girls' personal experiences in relation to program elements. For instance, this may include feminist and critical approaches that place a significant emphasis on the intersections between political, social, gendered, and racialized dimensions of youths' lives (Clonan-Roy, Jacobs, \& Nakkula, 2016; Oliver \& Hamzeh, 2010; Rauscher \& Cooky, 2016). We recognize the implications of our work, and youth-based work in general, to merge with activistbased researchers using participatory methods (for example, Oliver \& Kirk, 2015) as an intentional move toward further researching the nuanced intersectionality of girls' experiences in regard to PYD and after-school programs. This move would signal a more active and critical stance on examining and acting against the very social, political, and economic inequities that PYD after-school programs seek to counter. 
Journal of Youth Development | http://jyd.pitt.edu/ | Vol. 14 Issue 1 DOI 10.5195/jyd.2019.729

Girls' Experiences in a PYD Sport Program

\section{References}

Afterschool Alliance. (2016). America after 3pm special report: Afterschool in communities of concentrated poverty. Retrieved from http://www.afterschoolalliance.org/AA3PM/Concentrated_Poverty.pdf

Basch, C. E. (2011). Physical activity and the achievement gap among urban minority youth. The Journal of School Health, 81(10), 626-643. doi:10.1111/j.1746-1561.2011.00637.x

Bean, C., Forneris, T., \& Halsall, T. (2014). Girls just wanna have fun: A process evaluation of a female youth-driven physical activity-based life skill program. SpringerPlus, 3(401), 1-15. doi:10.1186/2193-1801-3-401

Bean, C., Kendellen, K., \& Forneris, T. (2016). Moving beyond the gym: Exploring life skill transfer within a female physical activity-based life skills program. Journal of Applied Sport Psychology, 28(3), 274-290. doi:10.1080/10413200.2015.1124155

Belcher, B. R., Berrigan, D., Dodd, K. W., Emken, B. A., Chou, C., \& Spuijt-Metz, D. (2010). Physical activity in U.S. youth: Impact of race/ethnicity, age, gender and weight status. Medicine and Science in Sports and Exercise, 42(12), 2211-2221. doi:10.1249/MSS.0b013e3181e1fba9

Castelli, D. M., Hillman, C. H., Buck, S. M., \& Erwin, H. E. (2007) Physical fitness and academic achievement in third- and fifth-grade students. Journal of Sport \& Exercise Psychology, 29(2), 239-252. doi:10.1123/jsep.29.2.239

Centers for Disease Control and Prevention. (2007). Prevalence of regular physical activity among adults-United States, 2001 and 2005. Morbidity and Mortality Weekly Report, 56(46), 12091212.

Clonan-Roy, K., Jacobs, C. E., \& Nakkula, M. J. (2016). Towards a model of positive youth development specific to girls of color: Perspectives on development, resilience, and empowerment. Gender Issues, 33(2), 96-121. doi:10.1007/s12147-016-9156-7

Creswell, J. W., \& Miller, D. L. (2000). Determining validity in qualitative inquiry. Theory into Practice, 39(3), 124-130. doi:10.1207/s15430421tip3903_2

Crosnoe, R. (2002). Academic and health-related trajectories in adolescence: The intersection of gender and athletics. Journal of Health and Social Behavior, 43(3), 317-335. doi:10.2307/3090207

Deutsch, N. L., Blyth, D. A., Kelley, J., Tolan, P. H., \& Lerner, R. M. (2017). Let's talk after-school: The promises and challenges of positive youth development for after-school research, policy, and practice. In N. Deutsch (Ed.) After-school programs to promote positive youth development: Integrating research into practice and policy, Volume 1 (pp. 45-68). Springer International Publishing.

Elsheikh, E., \& Barhoum, N. (2013). Structural racialization and food insecurity in the United States. A Report to the UN Human Rights Committee on the International Covenant on Civil and Political 
Journal of Youth Development | http://jyd.pitt.edu/ | Vol. 14 Issue 1 DOI 10.5195/jyd.2019.729

Girls' Experiences in a PYD Sport Program

Rights. Retrieved from https://haasinstitute.berkeley.edu/structural-racialization-food-insecurityus

Evans, G. (2004). The environment of childhood poverty. American Psychologist, 59(2), 77-92. doi:10.1037/0003-066X.59.2.77

Hirsch, B. J., Roffman, J. G., Deutsch, N. L., Flynn, C. A., Loder, T. L., \& Pagano, M. E. (2000). Inner-city youth development organizations: Strengthening programs for adolescent girls. The Journal of Early Adolescence, 20(2), 210-230. doi:10.1177/0272431600020002005

Hirsch, E. D. (2003). Reading comprehension requires knowledge-of words and the world. American Educator, 27(1), 10-13.

Holt, N. L., Neely, K. C., Slater, L. G., Camiré, M., Côté, J., Fraser-Thomas, J., . . \& \& Tamminen, K. A. (2017). A grounded theory of positive youth development through sport based on results from a qualitative meta-study. International Review of Sport and Exercise Psychology, 10(1), 1-49. doi:10.1080/1750984X.2016.1180704

Iachini, A. L., Beets, M. W., Ball, A., \& Lohman, M. (2014). Process evaluation of "Girls on the Run": Exploring implementation in a physical activity-based positive youth development program. Evaluation and Program Planning, 46, 1-9. doi:10.1016/j.evalprogplan.2014.05.001

Iachini, A. L., Bell, B. A., Lohman, M., Beets, M. W., \& Reynolds, J. F. (2016). Maximizing the contribution of after-school programs to positive youth development: Exploring leadership and implementation within Girls on the Run. Children \& Schools, 39(1), 43-52. doi:10.1093/cs/cdw045

Jones, J. N., \& Deutsch, N. L. (2011). Relational strategies in after-school settings: How staff-youth relationships support positive development. Youth \& Society, 43(4), 1381-1406. doi:10.1177/0044118X10386077

Larson, R. (2006). Positive youth development, willful adolescents, and mentoring. Journal of Community Psychology, 34(6), 677-689. doi:10.1002/jcop.20123

Larson, R. W., \& Walker, K. C. (2010). Dilemmas of practice: Challenges to program quality encountered by youth program leaders. American Journal of Community Psychology, 45(3-4), 338-349. doi:10.1007/s10464-010-9307-z

Lerner, R. M. (2004). Liberty: Thriving and civic engagement among America's youth. Thousand Oaks, CA: Sage.

Lerner, R. M. (2005). Promoting positive youth development through community and after-school programs. In J. L. Mahoney, R. W. Larson, \& J. S. Eccles (Eds.). Organized activities as contexts of development: Extracurricular activities, after school and community programs (ix-xii). Mahwah, NJ: Lawrence Erlbaum Associates.

Lerner, R. M., Almergi, J. B., Theokas, C., \& Lerner, J. V. (2005). Positive youth development: A view of the issues. The Journal of Early Adolescence, 25(1), 10-16. doi:10.1177/0272431604273211 
Journal of Youth Development | http://jyd.pitt.edu/ | Vol. 14 Issue 1 DOI 10.5195/jyd.2019.729

Girls' Experiences in a PYD Sport Program

Markowitz, E. S., Deutsch, N. L., \& Lawrence, E. (2014). Balancing skills and challenges: Exploring the concept of relational engagement in combined group and one-on-one mentoring for adolescent girls. Teachers College Record, 116(3), 146-165.

Marshall, C., \& Rossman, G. B. (2011). Designing qualitative research. Thousand Oaks, CA: Sage.

Molnar, B. E., Gortmaker, S. L., Bull, F. C., \& Buka, S. L. (2004). Unsafe to play? Neighborhood disorder and lack of safety predict reduced physical activity among urban children and adolescents. American Journal of Health Promotion, 18(5), 378-386. doi:10.4278/0890-117118.5.378

National Governors Association Center for Best Practices, Council of Chief State School Officers (2010). Common core state standards English language arts. Washington, DC: Author.

New York City Department of Education. (2017). Retrieved January 12, 2017 from https://www.schools.nyc.gov/about-us/reports/doe-data-at-a-glance.

Oliver, K. L., \& Hamzeh, M. (2010). "The boys won't let us play" Fifth-grade mestizas challenge physical activity discourse at school. Research Quarterly for Exercise and Sport, 81(1), 38-51. doi:10.1080/02701367.2010.10599626

Oliver, K. L., \& Kirk, D. (2015). Girls, gender and physical education: An activist approach. New York, NY: Routledge. doi:10.4324/9781315796239

Olushola, J. O., Jones, D. F., Dixon, M. A., \& Green, B. C. (2013). More than basketball: Determining the sport components that lead to long-term benefits for African-American girls. Sport Management Review, 16(2), 211-225. doi:10.1016/j.smr.2012.07.002

Rauscher, L., \& Cooky, C. (2016). Ready for anything the world gives her?: A critical look at sports-based positive youth development for girls. Sex Roles, 74(7-8), 288-298. doi:10.1007/s11199-0140400-x

Roth, J. L., \& Brooks-Gunn, J. (2003). Youth development programs: Risk, prevention and policy. Journal of Adolescent Health, 32(3), 170-182. doi:10.1016/S1054-139X(02)00421-4

Sanderson, R. C., \& Richards, M. H. (2010). The after-school needs and resources of a low-income urban community: Surveying youth and parents for community change. American Journal of Community Psychology, 45(3-4), 430-440. doi:10.1007/s10464-010-9309-x

Shen, B. (2017). Physical education and academic performance in urban African American girls. Urban Education, 52(2), 267-283. doi:10.1177/0042085914566095

Smith, E. P. (2007) The role of afterschool settings in positive youth development. Journal of Adolescent Health, 41(3), 219-220. doi:10.1016/j.jadohealth.2007.06.010

Staurowsky, E. J., DeSousa, M. J., Ducher, G., Gentner, N., Miller, K. E., Shakib, S., Theberge, N., \& Williams, N. (2009). Her life depends on it II: Sport, physical activity, and the health and wellbeing of American girls and women. East Meadow, NY: Women's Sports Foundation. 
Journal of Youth Development | http://jyd.pitt.edu/ | Vol. 14 Issue 1 DOI 10.5195/jyd.2019.729

Girls' Experiences in a PYD Sport Program

Troutman, K. P., \& Dufur, M. J. (2007). From high school jocks to college grads: Assessing the long-term effects of high school sport participation on females' educational attainment. Youth \& Society, 38(4), 443-462. doi:10.1177/0044118X06290651

Vandell, D. L., \& Shumow, L. (1999). After-school child care programs. The Future of Children, 9(2), 6480. doi:10.2307/1602707

Weiss, M. R., Stuntz, C. P., Bhalla, J. A., Bolter, N. D., \& Price, M. S. (2013). 'More than a game': Impact of The First Tee life skills programme on positive youth development: Project introduction and year 1 findings. Qualitative Research in Sport, Exercise and Health, 5, 214-244. doi:10.1080/2159676X.2012.712997 